\title{
A study to access the hemoglobin level and sociodemographic profile of under five children having Pica
}

\author{
Pandey D.C. ${ }^{1}$, Verma A. ${ }^{2}$, Abbas J. ${ }^{3}$, Saif M. ${ }^{4}$ \\ ${ }^{1}$ Dr. Dinesh Chandra Pandey, Professor \& Head, ${ }^{2}$ Dr. Ashish Verma, Associate Professor, ${ }^{3}$ Dr. Jaigam Abbas, Associate \\ Professor, ${ }^{4}$ Dr. Mohd. Saif, Assistant Professor; all authors are affiliated with Pediatrics Career Institute of Medical \\ Sciences, Lucknow, India.
}

Corresponding Author: Dr. Ashish Verma, Associate Professor, Pediatrics Career Institute of Medical Sciences, Lucknow, India. C-2/612, Jankipuram Sitapur Road, Lucknow, India. E-mail: ashish.paed81@gmail.com

\begin{abstract}
Introduction: Pica is a disorder that occurs when children persistently eat one or more non-food substances over the course of at least one month. Pica may result in serious medical problems, such as intestinal blockage, poisoning, parasitic infection, and sometimes death. The typical non-food substances that children with pica ingest tend to vary with age. Method: This prospective study was undertaken at a pediatric outdoor department Career Institute of Medical Sciences Lucknow since Jan 2019 to Mar 2019. All the under five years children visiting pediatric clinic with direct or indirect history of pica were enrolled for the study. The mothers were interviewed in depth regarding their sociodemographic profile and Hemoglobin level of all the children done. Results: In our study most of the children belongs to the age group 12-24 months 66(36.67\%). Most of the parents were educated upto secondary education only and belong to joint families.Children belongs to rural area $111(61.6 \%)$ were more in number and Only $87(48.33 \%)$ of the children were exclusive breast fed. In our study only $20.56 \%$ children have normal hemoglobin level while $79.44 \%$ children have hemoglobin level below $12.0 \mathrm{gm} / \mathrm{dl}$ and classified as anemic children, out of which $35.56 \%$ children have mild anemia, $25.00 \%$ children have moderate anemia and $18.89 \%$ children had severe anemia.Conclusion: Pica is mostly related with micronutrient deficiencies. Because of lower breastfeeding rate and delayed starting of complementary feeding the children are prone for micronutrient deficiencies leading to pica behavior in children. Knowledge of pica is the key for prevention.
\end{abstract}

Key words: Pica, Complementary feeding, Micronutrient deficiency.

\section{Introduction}

The word pica comes from the Latin word for magpie, a bird with a reputation for eating practically anything. The Diagnostic and Statistical Manual of Mental Disorders, 5th edition, defines pica as persistent eating of nonnutritive substances for at least 1 month that is inappropriate to developmental level and not part of a culturally supported or socially normative practice [1].

Pica is a disorder that occurs when children persistently eat one or more non-food substances over the course of at least one month. Pica may not sound like a dangerous problem, but when you consider that the non-food substances that are ingested are frequently toxic or otherwise harmful to the human body, the potential for illness and even death becomes clear. Pica may result in

Manuscript received: $20^{\text {th }}$ April 2019

Reviewed: $30^{\text {th }}$ April 2019

Author Corrected: $4^{\text {th }}$ May 2019

Accepted for Publication: $9^{\text {th }}$ May 2019 serious medical problems, such as intestinal blockage, poisoning, parasitic infection, and sometimes death. The typical non-food substances that children with pica ingest tend to vary with age. Younger children with Pica frequently eat paint, plaster, string, hair, or cloth. In contrast, older children with Pica tend to eat animal droppings, sand, insects, leaves, or pebbles [2].

Exploration of objects by mouthing and tasting is a part of normal, healthy development and is not considered pathological pica behavior. Pica is suspected only when (a) nonfood items are consumed repeatedly over the course of a month or long, despite efforts to curtail the behavior; (b) the behavior is considered inappropriate for the individual's developmental age (i.e., beyond the 18-month level); (c) it is not a cultural practice; and (d) the behavior is a symptom of another mental disorder and is of sufficient concern to warrant medical attention 


\section{Original Research Article}

(American Psychiatric Association, 1994)[3]. Pica has been shown to be the predisposing factor in accidental ingestion of poisons. The ingestion of bizarre or unusual substances also have been resulted in many potentially threatening toxicities such as gastrointestinal, including mechanical bowel problems, ulcerations, recurrent chest infections, anemia etc(2-5). Lead toxicity is the most common poisoning associated with pica [4]. In the light of these facts this study was planned and executed.

\section{Aims and Objective}

To study the demographic profile, and anemia status by using hemoglobin level of under five children having pica and to educate the parents about pica and its consequences.

\section{Material and Methods}

Type of study \& Setting: This prospective study was undertaken at a pediatric out patient department Career Institute of Medical Sciences Lucknow from Jan 2019 to Mar 2019.

Sampling method: The convenient sampling technique was adopted for the present study. Sample size was 180 .

Sampling technique: simple random sampling technique used for the study

Inclusion Criteria The study includes:

- All under five children having history of Pica attending pediatric department during study period.

- Parents were willing to take part in the study.

- Parents were able to understand Hindi or English.

\section{Results}

From January-2019 to till march-2019 we had enrolled total 180 underfive children with complain of pica, number of male children $98(54.4 \%$ ) outrages the females $82(45.56 \%)$, figure-1 depicts that in our study most of the children belongs to the age group 12-24 months and they are 66(36.67\%) while children of age group of $48-60$ months were least in numbers that is $37(20.56 \%)$.

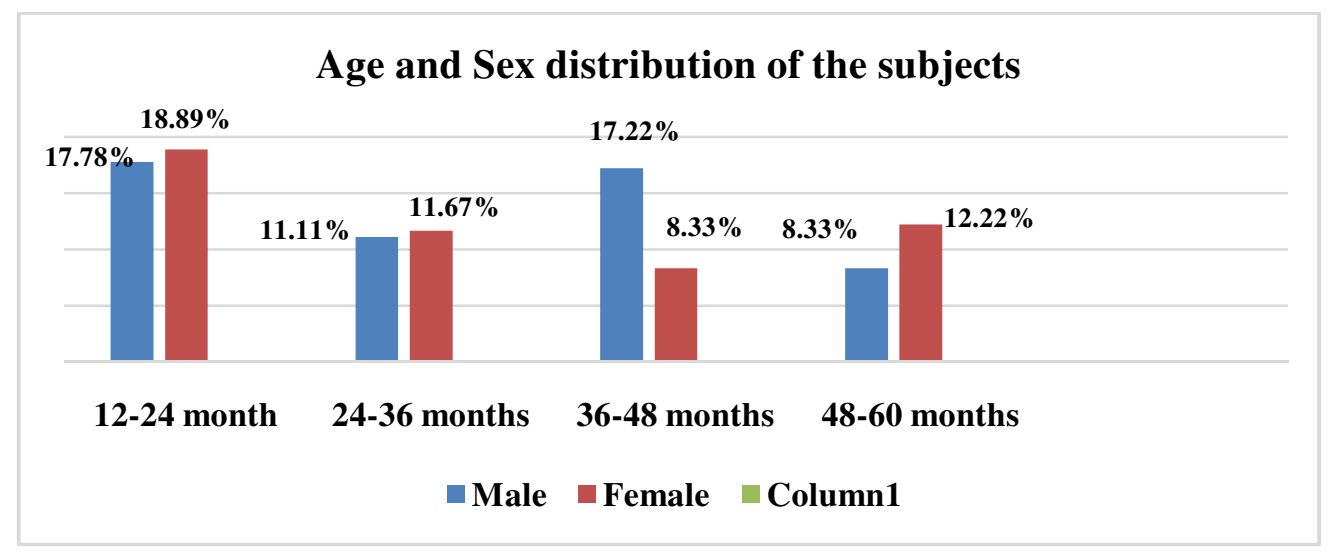

Figure-1: Age \& Sex Distribution (n=180) 


\section{Original Research Article}

Table-1: Mother and father's education status of the subjects.

\begin{tabular}{|l|c|l|c|}
\hline Mothers education & Total & Fathers education & Total \\
\hline No formal education & $14(07.78 \%)$ & No formal education & $13(07.22 \%)$ \\
\hline Up to Primary education only & $49(27.22 \%)$ & Up to Primary education only & $46(25.56 \%)$ \\
\hline Up to Secondary education only & $70(38.89 \%)$ & Up to Secondary education only & $67(37.22 \%)$ \\
\hline $\begin{array}{l}\text { Up to Higher Secondary } \\
\text { education only }\end{array}$ & $37(20.56 \%)$ & Up to Higher Secondary education only & $44(24.44 \%)$ \\
\hline Graduation and above & $10(05.56 \%)$ & Graduation and above & $10(05.56 \%)$ \\
\hline Total & $\mathbf{1 8 0}(\mathbf{1 0 0} \%)$ & Total & $\mathbf{1 8 0}(\mathbf{1 0 0} \%)$ \\
\hline
\end{tabular}

Most of the parents of the children were educated upto secondary education only (table-1)

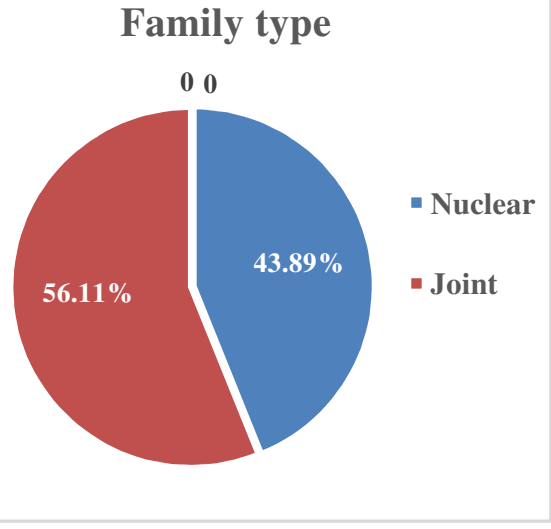

Figure-2: Family type of subjects

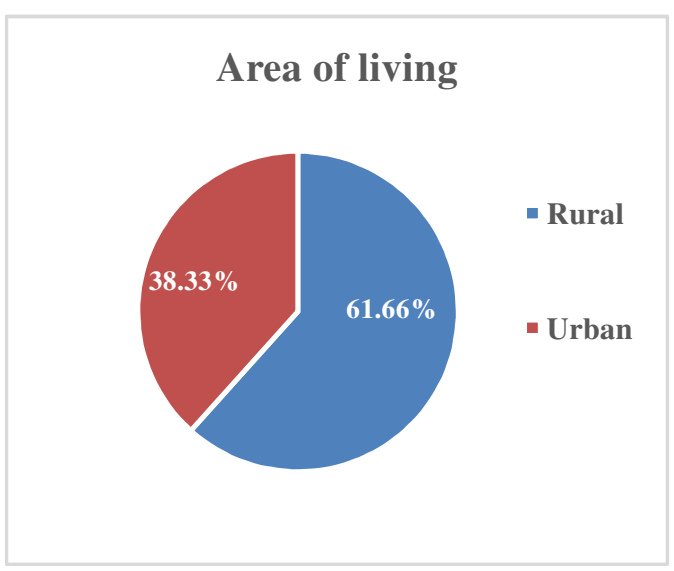

Figure-3: Area of living

Table-2: Exclusive breastfeeding status of the subjects.

\begin{tabular}{|c|c|c|c|c|c|}
\hline \multirow{2}{*}{ Age } & \multicolumn{2}{|c|}{ Male } & \multicolumn{2}{c|}{ Female } & \multirow{2}{*}{ Total } \\
\cline { 2 - 5 } & Yes & No & Yes & No & \\
\hline $12-24$ months & $18(10.00 \%)$ & $14(07.78 \%)$ & $12(06.67 \%)$ & $12(06.67 \%)$ & $56(31.11 \%)$ \\
\hline $24-36$ months & $11(6.11 \%)$ & $09(05.00 \%)$ & $09(05.00 \%)$ & $12(06.67 \%)$ & $41(22.78 \%)$ \\
\hline $36-48$ months & $14(7.78 \%)$ & $17(09.44 \%)$ & $06(03.33 \%)$ & $09(05.00 \%)$ & $46(25.56 \%)$ \\
\hline $48-60$ months & $07(03.89 \%)$ & $08(04.44 \%)$ & $10(5.56 \%)$ & $12(06.67 \%)$ & $37(20.56 \%)$ \\
\hline Total & $\mathbf{5 0}(\mathbf{2 7 . 7 8 \% )}$ & $\mathbf{4 8}(\mathbf{2 6 . 6 7 \%})$ & $\mathbf{3 7 ( 2 0 . 5 6 \% )}$ & $\mathbf{4 5}(\mathbf{2 5 . 0 0 \% )}$ & $\mathbf{1 8 0}(\mathbf{1 0 0} \%)$ \\
\hline
\end{tabular}

Most of the under five children belong to joint families 101(56.11\%). Children belongs to rural area 111(61.6\%) were more in number and Only $87(48.33 \%$ ) of the children were exclusive breast fed (table 2 ).

Table-3: Complementary feeding status of the subjects (started at 6 the age of 6 months).

\begin{tabular}{|c|c|c|c|c|c|}
\hline \multirow{2}{*}{ Age } & \multicolumn{2}{|c|}{ Male } & \multicolumn{2}{c|}{ Female } & \multirow{2}{*}{ Total } \\
\cline { 2 - 5 } & Yes & No & Yes & No & \\
\hline $12-24$ months & $12(06.67 \%)$ & $20(11.11 \%)$ & $14(07.78 \%)$ & $10(05.56 \%)$ & $56(31.11 \%)$ \\
\hline $24-36$ months & $08(04.44 \%)$ & $12(06.67 \%)$ & $09(05.00 \%)$ & $12(06.67 \%)$ & $41(22.78 \%)$ \\
\hline $36-48$ months & $14(07.78 \%)$ & $17(09.44 \%)$ & $08(04.44 \%)$ & $07(03.89 \%)$ & $46(25.56 \%)$ \\
\hline $48-60$ months & $06(03.33 \%)$ & $09(05.00 \%)$ & $09(05.00 \%)$ & $13(07.22 \%)$ & $37(20.56 \%)$ \\
\hline Total & $\mathbf{4 0}(\mathbf{2 2 . 2 2} \%)$ & $\mathbf{5 8}(\mathbf{3 2 . 2 2} \%)$ & $\mathbf{4 0}(\mathbf{2 2 . 2 2} \%)$ & $\mathbf{4 2}(\mathbf{2 3 . 3 3 \% )}$ & $\mathbf{1 8 0}(\mathbf{1 0 0} \%)$ \\
\hline
\end{tabular}

Table-3 shows that timely starting of complementary feeding was only 80 (44.44\%). 
Table-4 Presenting complain in children $(n=180)$.

\begin{tabular}{|c|c|c|c|}
\hline Presenting complains & Male & Female & Total \\
\hline Pica (direct) & $23(12.78 \%)$ & $17(09.44 \%)$ & $41(22.78 \%)$ \\
\hline Pica (indirect) & & & $26(14.44 \%)$ \\
\hline Fever & $12(06.67 \%)$ & $14(07.78 \%)$ & $21(11.67 \%)$ \\
\hline Cough/cold & $14(07.78 \%)$ & $07(03.89 \%)$ & $34(18.89 \%)$ \\
\hline Pain abdomen & $18(10.00 \%)$ & $16(08.89 \%)$ & $26(14.44 \%)$ \\
\hline Poor appetite & $15(08.33 \%)$ & $11(06.11 \%)$ & $11(06.11 \%)$ \\
\hline Loose motion & $04(02.22 \%)$ & $07(03.89 \%)$ & $09(05.00 \%)$ \\
\hline Vomiting & $06(3.33 \%)$ & $03(01.67 \%)$ & $08(4.44 \%)$ \\
\hline Lethargy & $03(01.67 \%)$ & $05(02.78 \%)$ & $04(2.22 \%)$ \\
\hline Passing worms in stool & $03(01.67 \%)$ & $01(0.56 \%)$ & $180(100 \%)$ \\
\hline Total & $98(54.44 \%)$ & $82(45.56 \%)$ & \\
\hline
\end{tabular}

Only 41(22.78\%) children have direct history of Pica as presenting complains while rest other children presented for various other complains like pain abdomen 34(18.89\%), fever 26(14.44\%), poor appetite 26(14.44\%), cough $21(11.67 \%)$, loose motion $11(06.11 \%)$, vomiting $09(05.00 \%)$, lethargy 08(04.44\%), passing worms in stool $04(02.22 \%)$ respectively in descending order.

Table-5: Type of material used for PICA $(n=180)$.

\begin{tabular}{|c|c|c|c|}
\hline Material & Male & Female & Total \\
\hline Clay/sand/mud/plaster & $66(36.67 \%)$ & $57(31.67 \%)$ & $123(68.33 \%)$ \\
\hline Uncooked rice/pulses & $41(22.78 \%)$ & $26(14.44 \%)$ & $67(37.22 \%)$ \\
\hline Papers & $27(15.00 \%)$ & $20(11.11 \%)$ & $47(26.11 \%)$ \\
\hline Cloths & $18(10.00 \%)$ & $19(10.56 \%)$ & $37(20.56 \%)$ \\
\hline Uncooked vegetable & $25(13.89 \%)$ & $28(15.56 \%)$ & $53(29.44 \%)$ \\
\hline Pencil/rubber/chalk & $23(12.78 \%)$ & $24(13.33 \%)$ & $46(25.56 \%)$ \\
\hline
\end{tabular}

Table 5 depicts that the material used for pica mostly was clay/sand/plaster 123(68.33\%), uncooked rice/pulses 67(37.22\%), uncooked vegetables 53(29.44\%), papers 47(26.11\%), pencil/rubber/chalk 46(25.56\%) and cloths $37(20.56 \%)$

Table-6: Children having Anemia (n=180).

\begin{tabular}{|c|c|c|c|}
\hline Haemoglobin level & Male & Female & Total \\
\hline More than 12(Normal) & $21(11.67 \%)$ & $16(08.89 \%)$ & $37(20.56 \%)$ \\
\hline $10-12 \mathrm{gm} / \mathrm{dl}($ Mild anemia) & $37(20.56 \%)$ & $27(15.0 \%)$ & $64(35.56 \%)$ \\
\hline $7-10 \mathrm{gm} / \mathrm{dl}($ Moderate anemia) & $23(12.78 \%)$ & $22(06.67 \%)$ & $45(25.00 \%)$ \\
\hline Less than 7 gm/dl(Severe anemia) & $17(09.44 \%)$ & $17(09.44 \%)$ & $34(18.89 \%)$ \\
\hline Total & $98(54.44 \%)$ & $82(45.56 \%)$ & $180(100 \%)$ \\
\hline
\end{tabular}

In our study only $37(20.56 \%)$ children had normal hemoglobin level while 64(35.56\%) children have mild anemia, $45(25.00 \%)$ children have moderate anemia and 34(18.89\%) children had severe anemia (table-6). 


\section{Discussion}

Pica is a quiet old condition but still pica remains a mysterious and fascinating occurrence. It seems to be strongly associated with iron deficiency anemia, and in the majority of cases the unusual eating and chewing behavior disappears upon iron supplementation $[5,6,7,8]$. Several hypotheses exist about why iron deficiency causes pica, including physiological mechanisms; however, there is no single agreed upon explanation [9]. When associated with iron deficiency, it is believed to be a symptom of the deficiency rather than its cause [9]. Occasionally, pica practices cause other nutritional deficiencies such as hypokalemia (clay and Kayexalate ingestion [10]).

There have been several theories explaining the causes of pica. Earlier investigators proposed thatpica practices compensated for nutritional deficiencies, such as iron or zinc, but this idea was discarded as ice, rubber, foam and several other items, consumed by those who practice pica, do not have any known nutritional value [11]. Interestingly, pica is practiced when a patient is least supervised. Patients are also secretive of their pica habits and are often reluctant to mention it. Pica symptoms will thus go unnoticed unless the physician specifically addresses them $[12,13]$.

In our study the number of male children $98(54.4 \%)$ exceeds the number of female $82(45.56 \%)$ children just like the study done by R K Gupta and Bhatia et al where the percentage of male children were $60 \%$, $58.82 \%$ and females were $40 \%, 41.18 \%$ respectively[14,15]. Because our institute is located in the rural area of the Lucknow district so the Children belongs to rural area 111(61.6\%) were more in number.

Most of the parents were educated up to secondary class only. The exclusive breast feeding rate was only $48.33 \%$ and the complementary feeding started at the age of six month in only in $44.44 \%$, because of lower breast feeding rate and delayed starting of complementary feeding the children are prone for micronutrient deficiencies leading to pica behavior in children [16] that is supported by study done by Singhi et al have demonstrated low levels of micronutrient like iron and zinc in children with pica[17].

In our study only $22.78 \%$ mothers had given direct history of Pica as presenting complain while in the study done by R K Gupta et al About 32\% mothers gave direct history of pica as presenting complains[15]. pica is a behavioral problem of developing children so the chances of child coming to hospital with complain of pica is less, most of the parents think that the problem of pica is related to the development and it will be corrected by its own as the child grow with time[16]. Some of the parents think that this problem is related with the micronutrient deficiencies so they come to hospital for the same. In the present study the material used for pica mostly was clay/sand/plaster in $68.33 \%$ because most of our study population belongs to rural area and the clay is easily available substance that's why used for eating.Our study finding is supported by the study of Bhatia etal, who had found in his study that $47.89 \%$ children were using clay to satisfy their pica behavior [15].

Pica is associated with many micronutrient deficiencies and vise versa. Most of the children with pica have parasitic infestation [18].Because of these micronutrient deficiencies, parasitic infestation and problem in absorption of iron due to these materials children are prone for anemia [19]. In our study only $20.56 \%$ children have normal hemoglobin level while $79.44 \%$ children have hemoglobin level below $12.0 \mathrm{gm} / \mathrm{dl}$ and classified as anemic children, out of which $35.56 \%$ children have mild anemia, $25.00 \%$ children have moderate anemia and $18.89 \%$ children had severe anemia.

These findings were supported by many studies suggestive of anemia in children like Bhatia et al., 2015 Ali, 2001; Hackworth \& Williams, 2003; Lemanek et al., 2002; Rose et al., 2000)[16,19,20,21]. Certain substances are shown to interfere with absorption of iron by the body; however, pica is more often seen as a physiological response to a preexisting iron deficiency [16].

Nutritional deficiencies can also result when individuals substitute nonfood items for calorie-bearing, nutritive foods [21]. Some picas pose serious health risks, which include toxicity; intestinal infections and/or parasites; malnutrition, anemia, and other nutritional deficiencies; oral and dental health problems; and intestinal obstruction/ perforation [23,24,25]. Indirect complications include being avoided by others and the danger of bodily harm related to the process of searching for desired items. In certain cases, pica may be life threatening [26].

Nutrient supplements are often used to reduce pica in individuals with and without DD. Iron supplements are recommended most often, and reductions of pica occur in some cases $[26,27,28]$. Pica is also some what 


\section{Original Research Article}

effectively treated with zinc supplements. In an institution in North Carolina, 54\% of residents with known pica behavior were judged to have low zinc levels. After supplementation, pica behavior decreased from 23 incidents to 4.3 incidents per person across a 2week period [29].

\section{Conclusion}

Pica is a common problem in children but most of the parents think that this is a problem related to the age of the children and it will subside by its onbut many studies including ours also has shown that pica is mostly related with anemia and micronutrient deficiencies and if parents are aware about it this will lead to avoidance of Pica and improving the health status of the children. Educating parents about pica is most important for prevention and treatment of Pica.

First and second author were major contributor in the collection of data and planning of study, while third and fourth author helped in data collection and compilation of data.

What this study adds to existing knowledge: Present study recommends that exclusive breast feeding upto the age of 6 months and initiation of complementary feeding at 6 months will be a preventive aspect of micronutrient deficiency leading to Pica. Knowledge about pica and its consequences are also very helpful to parents to avoid pica in their children.

Funding: Nil, Conflict of interest: None initiated, Perission from IRB: Yes

\section{References}

1. American Psychiatric Association. Diagnostic and Statistical Manual of Mental Disorders. 5th ed. Arlington, VA: American Psychiatric Association; 2013.

2. Andrea Barkoukis, M.A., Natalie Staats Reiss: Feeding And Eating Disorders Of Infancy Or Early Childhood: Pica; https://www.mentalhelp.net.

3.American Psychiatric Association. (1994). Diagnostic and statisticalmanual of mental disorders (4th ed.). Washington, DC: Author.

4. Ellis CR, Schnoes CJ. Eating disorder: Pica Med J 2002;3: 8 .

5. Coltman CA Jr. Pagophagia and iron lack. JAMA. 1969 Jan 20;207(3):513-6.
6. Kathula SK. Craving lemons: another form of pica in iron deficiency. Am J Med. 2008 Jul;121(7):e1. doi: 10.1016/j.amjmed.2008.02.017.

7. Kettaneh A, Eclache V, Fain O, et al. Pica and food craving in patients with iron-deficiency anemia: a casecontrol study in France. Am J Med. 2005 Feb;118(2): 185-8. DOI:10.1016/j.amjmed.2004.07.050

8. Pagophagia and anemia. Nutr Rev. 1969 Feb; 27(2):52-4. DOI: 10. 1111/j. 1753-4887. 1969. tb 04956.x

9. Grivetti LE. Culture, diet and nutrition: selected themes and topics. Bio Science. 1978; 28 (3): 171-177.

10. Barker D. Tooth wear as a result of pica. Br Dent J. 2005 Sep 10; 199 (5): 271-3. DOI: 10. 1038/sj.bdj. 4812651

11. Ukaonu C, Hill DA, Christensen F. Hypokalemic myopathy in pregnancy caused by clay ingestion. Obstet Gynecol. 2003 Nov; 102 (5 $\quad$ Pt $\quad$ 2): 1169-71.

12. Falcomata TS, Roane HS, Pabico RR. Unintentional stimulus control during the treatment of pica displayed by a young man with autism. RASD. 2007. pp. $350-359$.

13. Scully RE, Mark EJ, McNeely WF, Ebeling SH, et al. Case records of the Massachusetts General Hospital. Weekly clinicopathological exercises. Case 20-1997. A 74-year-old man with progressive cough, dyspnea, and pleural thickening. N Engl J Med. 1997 Jun 26;336 (26):1895-903.

14. Ravinder K. Gupta, RituGupta.Clinical Profile of Pica in Childhood. Jksciences 2005; 7 (2)

15. Ravi Bhatia, Dr. Gunjan Bhatia.Pattern, beliefs associated with Pica in children aged 1-10 years- A studyof 119 cases.Indian Journal of Basic and Applied Medical Research; Dec 2015;5(1).

16. Jin Soo Moon.Nutritional management of breastfeeding infants for the prevention of common nutrient deficiencies and excesses.Korean J Pediatr. 2011; 54(7)

17. Singhi S, Ravishanker R, Singhi P, et al. Low plasma zinc and iron in pica. Indian J Pediatr. 2003 Feb; 70 (2):139-43. 


\section{Original Research Article}

18. Robinson, B. A., Tolan, W., \& Golding-Beecher, O. (1990). Childhood pica: Some aspects of the clinical profile in Manchester, Jamaica. West Indian Medical Journal, 39, 20-26.

19. Ali, Z. (2001). Pica in people with intellectual disability: A literature review of aetiology, epidemiology and complications. Journal of Intellectual and Developmental Disability, 26, 205-215.

20. Hackworth SR, Williams LL. Pica for foam rubber in patients with sickle cell disease. South Med J. 2003 Jan; 96 (1): 81-3. DOI: 10.1097/01.SMJ.0000047974. $56740.1 \mathrm{~A}$

21. Lemanek, K. L., Brown, R. T., Armstrong, F. D., Hood, C., Pegelow, C., \& Woods, G. (2002). Dysfunctional eating patterns and symptoms of pica in children and adolescents with sickle cell disease. Clinical Pediatrics, 41(7), 493-500.

22. Rose EA, Porcerelli JH, Neale AV. Pica: common but commonly missed. J Am Board Fam Pract. 2000 Sep-Oct; 13(5):353-8.

23. Duker PC, Nielen M. The use of negative practice for the control of pica behavior. J Behav Ther Exp Psychiatry. 1993 Sep;24(3):249-53.
24. Santiago-Sanchez, C. A., Garau-Diaz, P., \& LugoVicente, H. L.(1996). Trichobezoar in an 11-year-old girl: A case report. Pediatric Surgery Update [online serial]. Retrieved from http://home.coqui.net/ titolugo/ articles.htm.

25. Wahbeh, G., Wyllie, R., \& Kay, M. (2002). Foreign body ingestion in infants and children: Location, location, location. Clinical Pediatrics, 41, 633-640

26. Burke, L., \& Smith, S. L. (1999). Treatment of pica: Considering least intrusive options when working with individuals who have a developmental handicap and live in a community setting. Developmental Disabilities Bulletin, 27(1). Retrieved from http://www.ualberta. ca/ jpdasddc/bulletin/articles/burke1999.html.

27. Katsiyannis, A., Torrey, G., \& Bond, V. Current considerations in treating pica. Teaching Exceptional Children, 1998;30(4), 50-53.

28. Kirchner, J. Management of pica: A medical enigma. American Family Physician,2001; 63, 1177

29. Lofts RH, Schroeder SR, Maier RH. Effects of serum zinc supplementation on pica behavior of persons with mental retardation. Am J Ment Retard. 1990 Jul;95 (1): 103-9.

\section{How to cite this article?}

Pandey D.C, Verma A, Abbas J, Saif M. A study to access the hemoglobin level and sociodemographic profile of underfive children having Pica. Int J Pediatr Res. 2019;6(05):194-200.doi:10.17511/ijpr.2019.i05.01 